\title{
Case Report \\ Breast Metastasis in Esophagus Cancer: Literature Review and Report on a Case
}

\begin{abstract}
Abdulaziz Ghibour and Osama Shaheen
Department of General Surgery, Al-Mouwasat University Hospital, Faculty of Medicine, Damascus University, 5371 Damascus, Syria

Correspondence should be addressed to Osama Shaheen; shaheenosama@hotmail.com

Received 8 March 2016; Revised 2 May 2016; Accepted 11 May 2016

Academic Editor: Oded Olsha

Copyright ( 2016 A. Ghibour and O. Shaheen. This is an open access article distributed under the Creative Commons Attribution License, which permits unrestricted use, distribution, and reproduction in any medium, provided the original work is properly cited.

Esophagus cancer metastases often involve locoregional lymph nodes, lung, bone, liver, and brain. Metastatic involvement of the breast from esophagus cancer is uncommon, but if it happened, it usually presents as a part of multiple organ distal metastases. Here we report a case of the largest metastatic esophagus cancer of the breast and the chest wall, and we review the similar reported cases.
\end{abstract}

\section{Introduction}

Esophagus cancer metastases to unexpected sites usually happen when there are widespread metastases to other organs [1], and breast is considered one of the unexpected sites for esophageal cancer metastasis. Here, in order to understand more about this rare phenomenon, we conducted a literature review using Medline, PubMed, and Google Scholar on all the cases that described breast metastasis from esophagus cancer. We report as well a remarkable case with the largest breast metastasis from esophagus cancer.

\section{Case Report}

A 57-year-old woman presented to our clinic with a painful left breast mass (Figure 1). The mass started to appear six months previously and gradually increased in size to become painful and tense, but without discharge from the nipple.

Her past medical history revealed she had been diagnosed with esophagus carcinoma one year ago (Figure 2), but she had refused any kind of treatment back then. Review of her other symptoms showed that the dysphagia associating the esophagus cancer had increased gradually during the last year until it became impossible for her to swallow any solid food during the last month, and she had lost $25 \mathrm{~kg}$ during the previous four months.
The patient was severely malnourished, her BMI was $14 \mathrm{~kg} / \mathrm{m}^{2}$, and her vital signs were as follows: Bp: 100/55 mm/ Hg; pulse: 130 beats per minute; temperature: $99.5 \mathrm{~F}$; RR: 22 breath per minute; she was alert and oriented but looked tired. The examination showed a fixed $9 \times 10 \times 7 \mathrm{~cm}$ painful hard mass involving the left breast. The skin over the mass was red but not hot and the rest of the examination including the lymphatic system was unremarkable except a noticeable wheezing in the right chest.

The blood tests were normal except for a decrease in TP and ALB and a mild decrease in calcium. The head, chest, and abdominal CT scan showed a $4 \times 6 \times 7 \mathrm{~cm}$ lobulated mass involving the lower third of the esophagus accompanied with a large $(10 \times 9.5 \times 8 \mathrm{~cm})$ lobulated (with necrotic component) mass involving the left breast, the left chest muscles, and the pleura; this mass is compressing the anterior face of the lung and destroying the accompanied ribs (Figure 3); the CT scan showed as well left and right pleural effusions without any other obvious metastasis.

Review of her medical history revealed moderately differentiated squamous cell carcinoma of the mid-lower third of the esophagus. The breast biopsy showed solid cords, sheets, and lobules of pleomorphic malignant epithelial cells with occasional bizarre, hyperchromic nuclei with occasional keratin pearls compatible with poorly differentiated squamous cell carcinoma (Figures 4 and 5). The pleural effusion examination was negative for malignancy. 


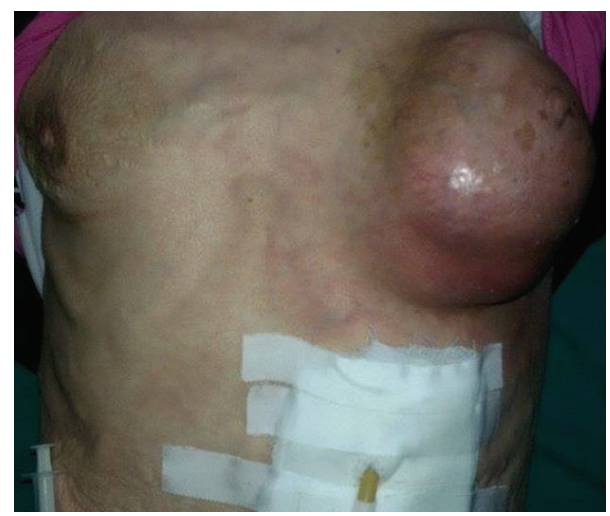

FIGURE 1: Left breast mass with gastrostomy.

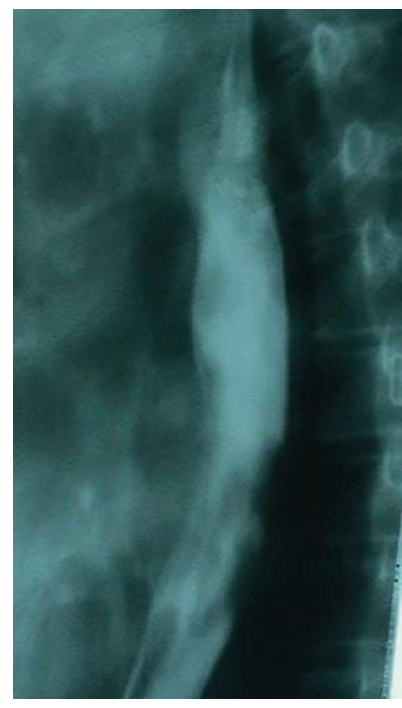

FIGURE 2: Esophagogram showing signs of mid-lower esophagus mass.

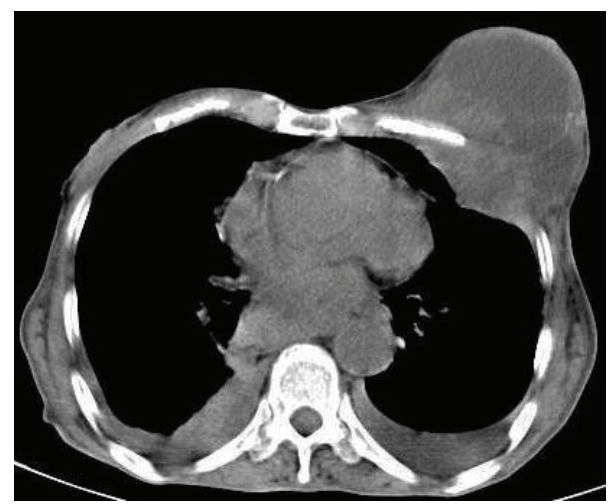

FIGURE 3: Oral and intravenous contrast-enhanced CT scan of the chest revealed bilateral pleural effusions with breast mass involving the left chest muscles and pleura destroying the rips.

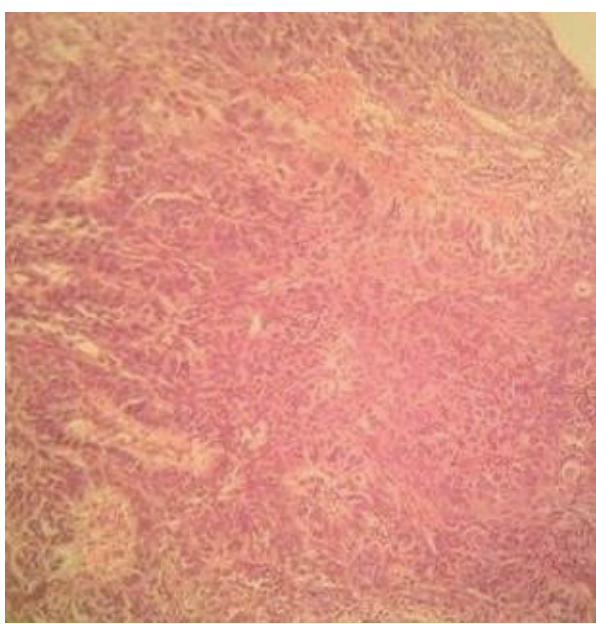

FIGURE 4: Histological view of the breast mass showing typical structure squamous cell carcinoma (hematoxylin and eosin, $\times 100$ ).

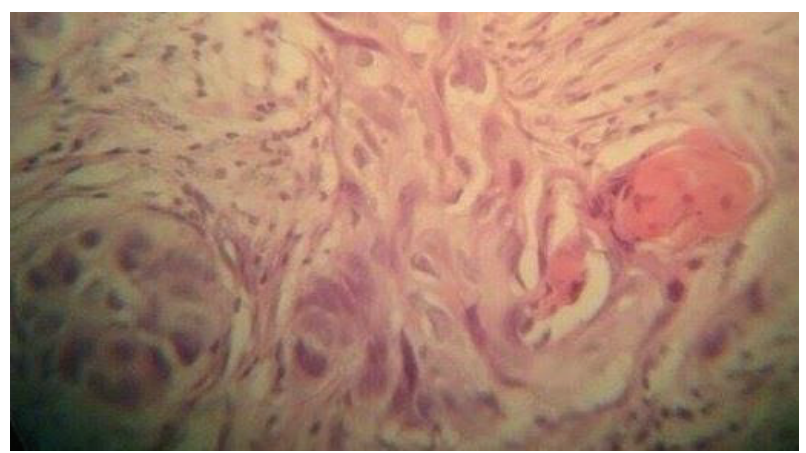

FIgURE 5: Histological view of the breast mass showing typical structure squamous cell carcinoma (hematoxylin and eosin, $\times 100$ ).

Feeding tube gastrostomy was done to the patient; however, she passed away two months later.

\section{Discussion}

In this study we did a literature review to the cases that described metastatic breast disease from esophagus cancer; we will report the clinical, radiological, and pathological features of the breast metastasis and we will review the diagnostic and the treatment options.

Only six cases were found in literature; besides our case the cases were 6 females and one male summarized in Table 1; the tumors were located in the middle and/or lower esophagus in 6 cases (squamous cell carcinoma (SSC) in five cases and adenocarcinoma in one case); only one case was reported as SCC in the upper middle part. These metastases were presented at variable times after the diagnosis of the original tumor ( 2 to 24 months); only one case reported the metastasis as the first sign of the esophagus cancer [2].

The physical examination of the breast metastasis demonstrated masses indistinguishable from primary mammary carcinoma, although they were often circumscribed and were described as painful in 3 cases. The metastasis size ranges 


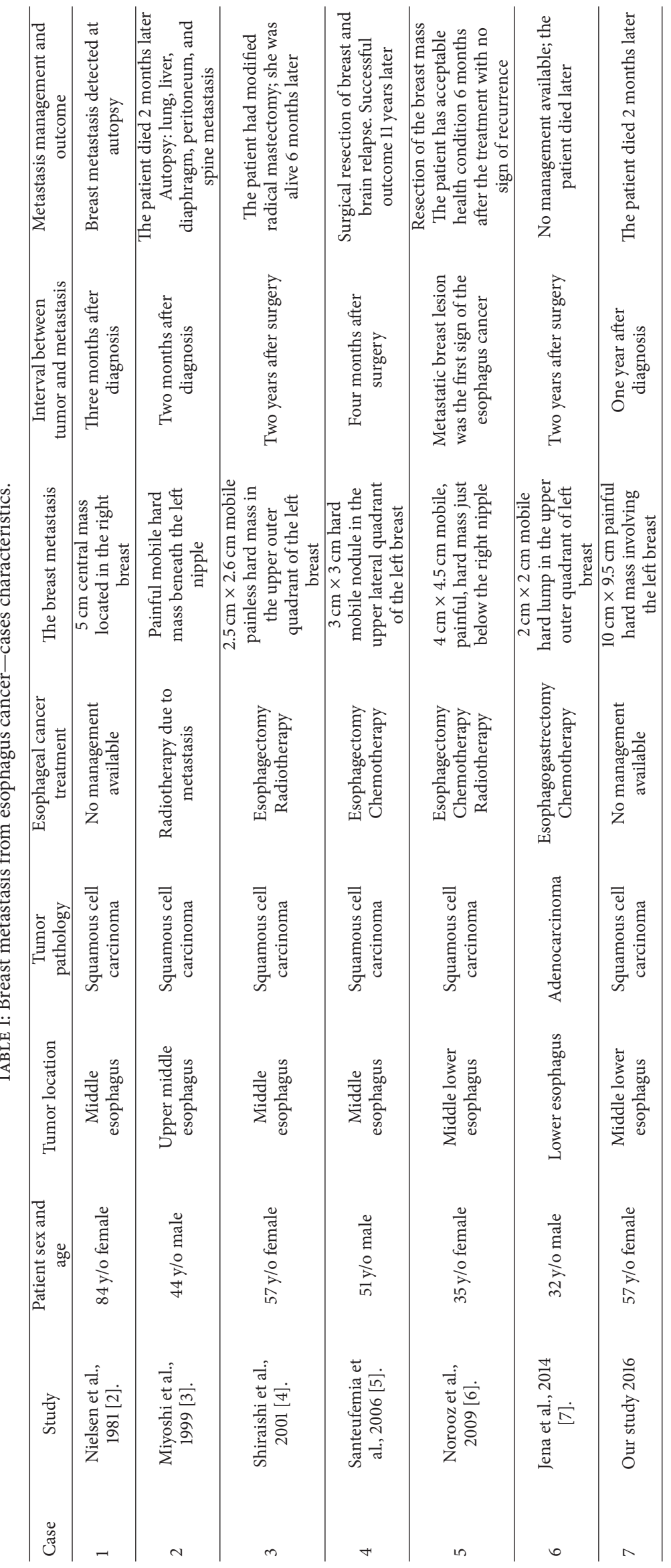


from 2 to $5 \mathrm{~cm}$ but it was remarkably larger in our case and reached $10 \mathrm{~cm}$ to completely involve the left breast, the left chest muscles, and the pleura. The metastases were located in the left breast in 5 cases and in the right breast in 2 cases.

The mammography was done in 5 cases and was negative for microcalcification. Core-needle or excisional biopsies were used for pathological diagnoses since immunohistochemistry and the presence of an in situ component play an important role in differentiating between primary and metastatic tumors [6]. Immunohistochemistry was always negative for ER, PR, and Her2 neu. In this review breast metastasis was the only recurrence in two cases, and acceptable results without signs of recurrence were mentioned up to six months after surgical resection of the breast metastasis. Only one case reported successful breast and brain metastasis resection outcome 11 years later. In our case, an autopsy was not done to the patient and she refused the treatment from the beginning; nevertheless, the large breast metastasis that involved the chest muscles and the pleura was the only detectable metastasis on CT scan. Three cases out of seven mentioned the presence of multiple untreatable metastasis during management or diagnosis.

We found that many case reports and some experimental studies were published trying to emphasize the complexity of esophagus cancer metastases patterns; these studies found that the complex anatomical pathway of the esophagus lymphatic network can elucidate the possibility of the random distribution of the metastases in esophagus cancer [8]. Despite the high frequency of distant metastasis to the lung, bone, liver, and brain observed in esophagus carcinoma, only a few cases were reported as being related to metastatic breast disease.

The studies showed that the lymphatics originating from the thoracic esophagus frequently drain into the thoracic duct directly without intervening lymph nodes $[8,9]$; since the thoracic duct has multiple collateral branches with the intercostal vessels, it can reach the internal mammary chain and may spread to the breast.

In general, treatment should be directed to the primary malignancy; usually the prognosis is poor and surgical resection of breast metastasis suffices only if metastases in other sites are not present or being controlled [5].

In conclusion breast metastasis in esophagus cancer is an extremely rare disease; the diagnosis should be highly suspected in any breast mass with a previous history of esophagus cancer, especially in the presence of multiple metastases. When the breast mass is the only reported metastasis, the case reports revealed that the surgical excision of the metastasis showed an acceptable result on the shorttime follow-up; however, more studies are needed for correct treatment choices. We reported the largest breast metastasis in esophagus cancer that involved the left chest muscle and the pleura, without any other obvious radiological metastases. The possibility of this phenomenon may elucidate part of the anatomical network pathway of esophagus cancer.

\section{Competing Interests}

The authors declare that there are no competing interests related to this paper.

\section{References}

[1] A. Ribeiro-Silva, C. F. Mendes, I. S. Costa, H. B. De Moura, D. G. Tiezzi, and J. M. Andrade, "Metastases to the breast from extramammary malignancies: a clinicopathologic study of 12 cases," Polish Journal of Pathology, vol. 57, no. 3, pp. 161-165, 2006.

[2] M. Nielsen, J. A. Andersen, F. W. Henriksen et al., "Metastases to the breast from extramammary carcinomas," Acta Pathologica et Microbiologica Scandinavica, vol. 89, no. 4, pp. 251-256, 1981.

[3] K. Miyoshi, S. Fuchimoto, T. Ohsaki et al., "A case of esophageal squamous cell carcinoma metastatic to the breast," Breast Cancer, vol. 6, no. 1, pp. 59-61, 1999.

[4] M. Shiraishi, T. Itoh, K. Furuyama et al., "Case of metastatic breast cancer from esophageal cancer," Diseases of the Esophagus, vol. 14, no. 2, pp. 162-165, 2001.

[5] D. A. Santeufemia, G. Piredda, G. M. Fadda et al., "Successful outcome after combined chemotherapeutic and surgical management in a case esophageal cancer with breast and brain relapse," World Journal of Gastroenterology, vol. 12, no. 34, pp. 5565-5568, 2006.

[6] M. T. Norooz, L. Montaser-Kouhsari, H. Ahmadi, M. J. Zavarei, and P. Daryaei, "Breast mass as the initial presentation of esophageal carcinoma: a case report," Cases Journal, vol. 2, no. 7, article 7049, 2009.

[7] S. Jena, S. Bhattacharya, A. Gupta, S. Roy, and N. K. Sinha, "Breast metastasis from esophagogastric junction cancer: a case report," Case Reports in Surgery, vol. 2014, Article ID 489427, 4 pages, 2014.

[8] G. Murakami, I. Sato, K. Shimada, C. Dong, Y. Kato, and T. Imazeki, "Direct lymphatic drainage from the esophagus into the thoracic duct," Surgical and Radiologic Anatomy, vol. 16, no. 4, pp. 399-407, 1994.

[9] M. Riquet, F. Le Pimpec Barthes, R. Souilamas, and G. Hidden, "Thoracic duct tributaries from intrathoracic organs," Annals of Thoracic Surgery, vol. 73, no. 3, pp. 892-898, 2002. 


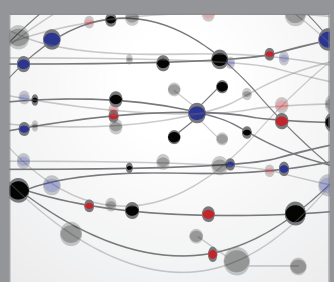

The Scientific World Journal
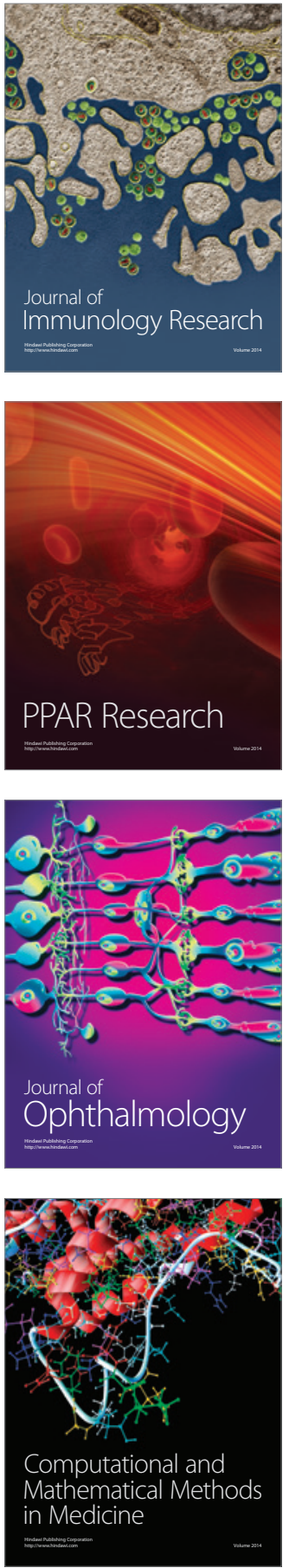

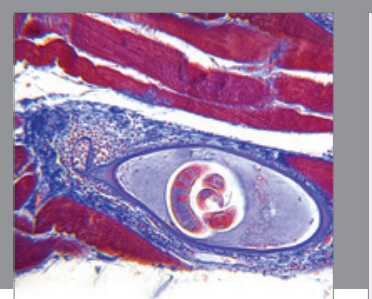

Gastroenterology Research and Practice

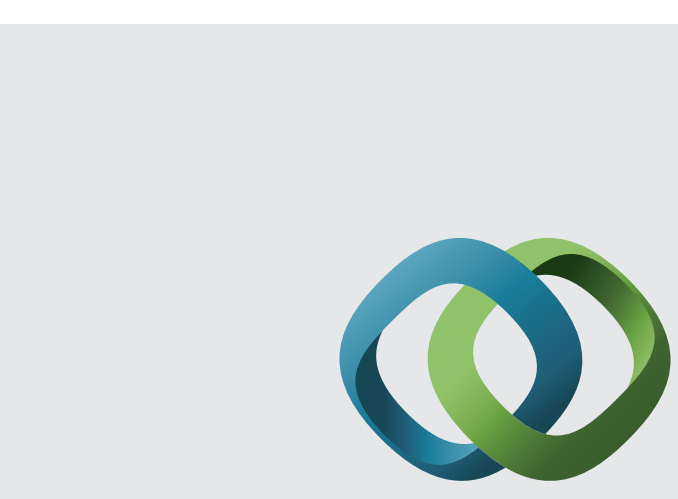

\section{Hindawi}

Submit your manuscripts at

http://www.hindawi.com
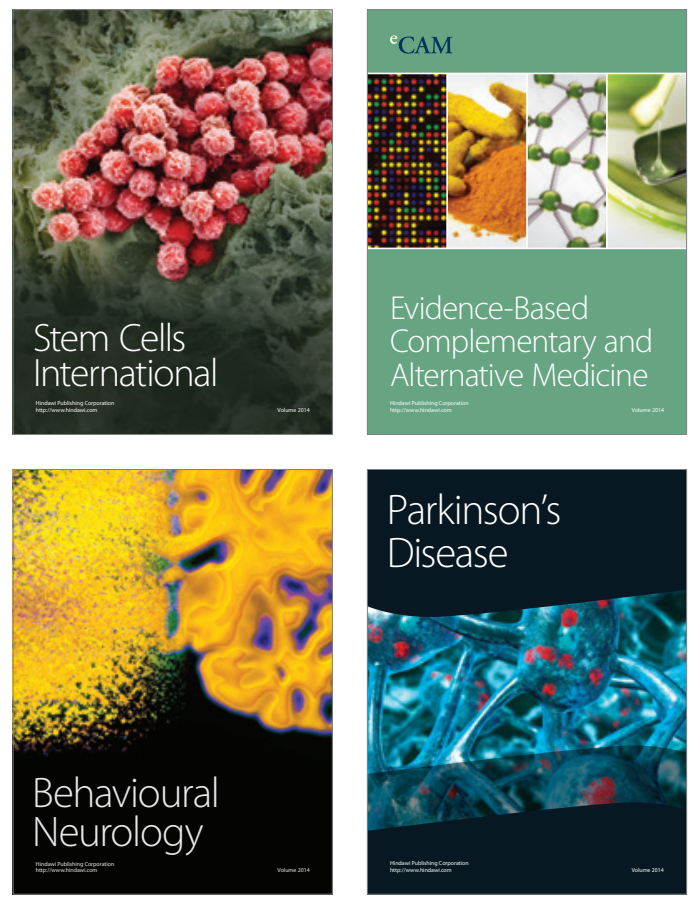
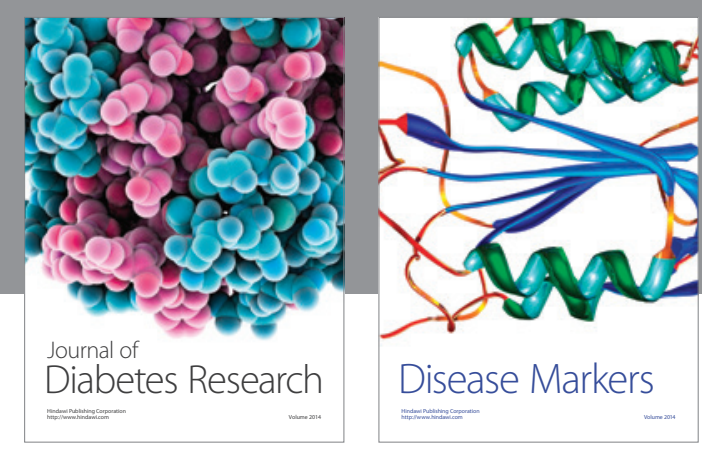

Disease Markers
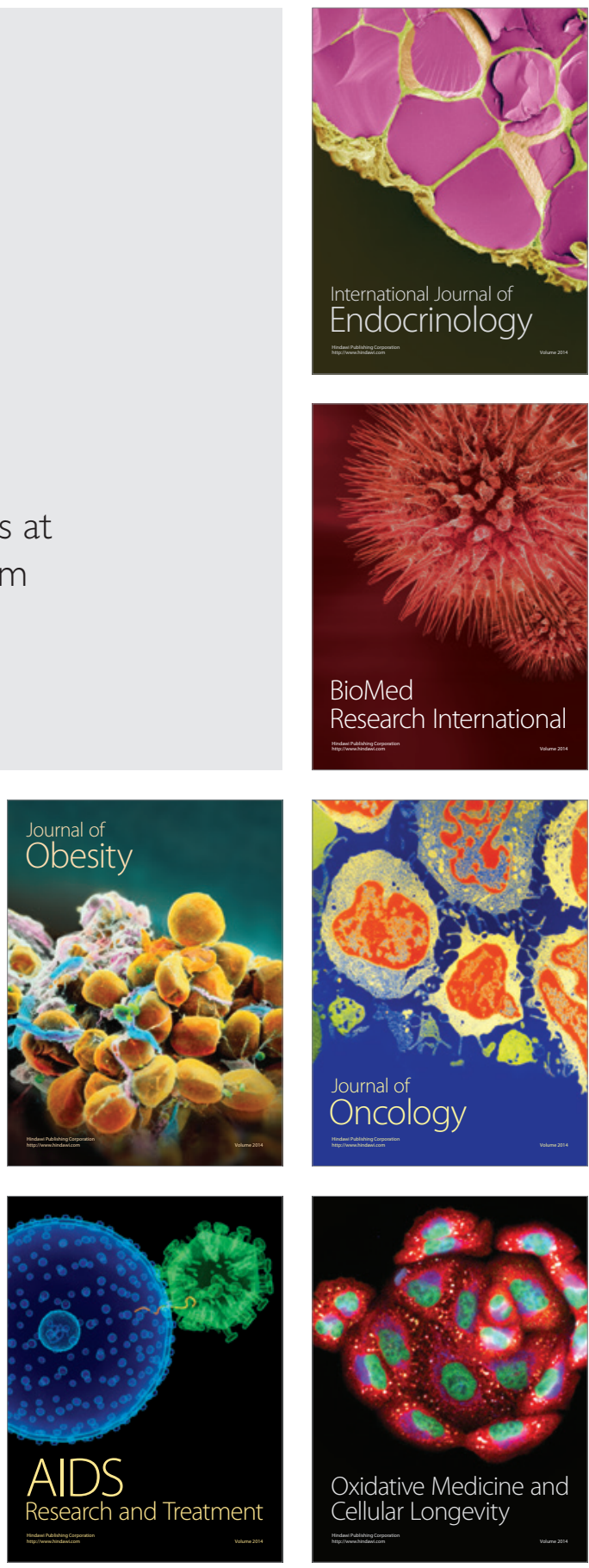